\section{Güliz N. Güncü \\ Yagmur D. Yildirim \\ Hom-Lay Wang \\ Tolga F. Tözüm}

\title{
Location of posterior superior alveolar artery and evaluation of maxillary sinus anatomy with computerized tomography: a clinical study
}

Key words: computerized tomography, dental implants, posterior superior alveolar artery, sinus pathology, sinus septa

Güliz N. Güncü, Yagmur D. Yildirim, Tolga F. Tözüm, Department of Periodontology, Faculty of Dentistry, Hacettepe University, Ankara, Turkey

Hom-Lay Wang, Department of Periodontics and Oral Medicine, School of Dentistry, The University of

Michigan, Ann Arbor, MI, USA

Corresponding author:

Dr Tolga F. Tözüm

Department of Periodontology

Faculty of Dentistry

Hacettepe University

3rd Floor, Sihhiye 06 Ioo

Ankara

Turkey

Tel.: +90 3 I 23052237

Fax: + 903 I 23 IO 444 O

e-mail: ttozum@hacettepe.edu.tr

Date:

Accepted I4 August 2010

To cite this article:

Güncü GN, Yildirim YD, Wang H-L, Tözüm TF. Location of posterior superior alveolar artery and evaluation of maxillary sinus anatomy with computerized tomography: a clinical study.

Clin. Oral Impl. Res. 22, 201 I; I I 64-I I 67.

doi: Io.I I I I/j. I600-050I.20I0.0207I.X

\section{Abstract}

Objectives: Knowledge and evaluation of the maxillary sinus anatomy before sinus augmentation are essential for avoiding surgical complications. Posterior superior alveolar artery (PSAA) is the branch of maxillary artery that supplies lateral sinus wall and overlying membrane. The aims of this study were to examine the prevalence, diameter, and location of the PSAA and its relationship to the alveolar ridge and to study the prevalence of the sinus pathology and septum using computerized tomography (CT) scans. Materials and methods: One hundred and twenty-one CT scans ( 242 sinuses) from patients undergoing sinus augmentation procedure and/or implant therapy were included. Lower border of the artery to the alveolar crest, bone height below the sinus floor to the ridge crest, distance of the artery to the medial sinus wall, diameter of the artery, and position of the artery were measured; presence of septa and pathology were recorded from CT sections.

Results: Prevalence of sinus septa and sinus pathology was $16.1 \%$ and $24.8 \%$, respectively. Artery was seen in $64.5 \%$ of all sinuses and was mostly intraosseous (68.2\%). Mean diameter of PSAA was found $1.3 \pm 0.5 \mathrm{~mm}$. No significant correlation between the diameter of the artery and age was observed.

Conclusions: The results from this study suggested that CT scan is a valuable tool in evaluating presence of sinus pathology, septa, and arteries before maxillary sinus surgery. Although variations exist in every patient, the findings from this study suggest limiting the superior border of the lateral window up to $18 \mathrm{~mm}$ from the ridge to avoid any potential vascular damage.

Sufficient bone quantity and quality are essential for proper dental implant placement. This is especially the case in the posterior maxilla where resorption of alveolar bone and pneumatization of maxillary sinus cavity often compromises dental implant therapy. Sinus augmentation has evolved into a predictable surgical modality for increasing the vertical height that is needed for the successful placement of dental implants (Jensen et al. I998; Tong et al. I998). Understanding of regional nutritive arteries can allow clinicians to prevent local bone necrosis but also optimize regional healing via proper vascularization of the graft materials (Traxler et al. I999). The blood supply of the maxillary sinus and Schneiderian membrane comes from the maxillary artery. Posterior superior alveolar artery (PSAA) and infraorbital artery (IOA) are the branches of maxillary artery that supplies lateral sinus wall and overlying membrane. Both arteries give extra osseous and intraosseous branches and these branches form anastomosis. PSAA runs caudally on the outside of the convexity of the maxillary tuberosity and is in close contact with bone and periosteum (Solar et al. I999; Traxler et al. I999). The courses of the intraosseous branch of PSAA on the buccal wall of the sinus were classified into two categories: the straight $(\mathrm{S})$ type $(78 . \mathrm{I} \%)$ and the U shaped (2I.9\%) (Hur et al. 2009). Maximum diameters of the PSAA and IOA may reach to 2 and $2.7 \mathrm{~mm}$ (Solar et al. I999). The larger the size, the greater the risk of bleeding severity. These vessels should be taken into consideration during sinus augmentation because of the potential risk of bleeding during the procedure (Ella et al. 2008). The sinus augmentation procedure, first published by Boyne \& James (I980), was then modified to include both crestal and lateral window techniques (Tatum I986). Membrane perforations and bleeding are procedure-related complications, seen in lateral wall sinus approach (Regev et al. I995). Therefore, the anatomy of the area should be carefully examined before surgical interventions. 
Computerized tomography $(\mathrm{CT})$ is a digital imaging technique that enables differentiation and quantification of soft and hard tissues. Arteries and other anatomical structures can be examined in CT images. Septa can make the complete preservation of the sinus membrane more difficult as they can hamper the preparation and elevation of the bony window (Shibli et al. 2007). Prevalence of sinus septa ranges between I $6 \%$ and $27 \%$ (Krennmair et al. I997; Krennmair et al. I999; Shibli et al. 2007; Gosau et al. 2009). CT can also be used to evaluate bone dimension, recognize specific anatomical landmarks, and to detect sinus pathologies. Hence, the aim of this study was to examine the prevalence, diameter, and location of the PSAA and its relationship to the alveolar ridge and to study the prevalence of the sinus pathology and septum using CT scans.

\section{Materials and methods}

\section{Evaluation of CT scans}

One hundred and twenty-one CT (Siemens AR-SP 40, Siemens, Munich, Germany) scans $(242$ sinuses) from patients undergoing sinus augmentation procedure and/or implant therapy at the Department of Periodontology, Hacettepe University, were included in this clinical study. Seventy-two patients were female and 49 were male patients. Mean age was $48.73 \pm$ I I.86 years. Only highquality computerized images, axial sections with I mm intervals, were included in the study; excluded were images of low quality such as scattering and inferior level of window exposure. Scans were read by one calibrated investigator with a digital caliper (Mardinger et al. 2007). Intraexaminer variance was measured during the study on CT scans by having Ioo scans read twice by the reviewer. The two readings were separated by at least I month, and the Ioo CT scans were selected randomly.

Three sections, one axial section where the artery was first seen, the last section seen and one between these 2 sections, were evaluated for the below parameters.

I. Lower border of the artery to the alveolar crest: the vertical line from the artery to the crest (Elian et al. 2005).

2. Height of the bone below the sinus floor to the ridge crest.

3. Distance of the artery to the medial sinus wall (Mardinger et al. 2007).

4. Diameter of the artery: diameter was divided into three categories: (a) diameter < I mm, (b) diameter I-2 mm, and (c) diameter $\geq 2 \mathrm{~mm}$ (Mardinger et al. 2007).

5. Position of the artery [intraosseous (Fig. I), below the membrane (Fig. 2), on the outer cortex of the lateral sinus wall (Fig. 3)].

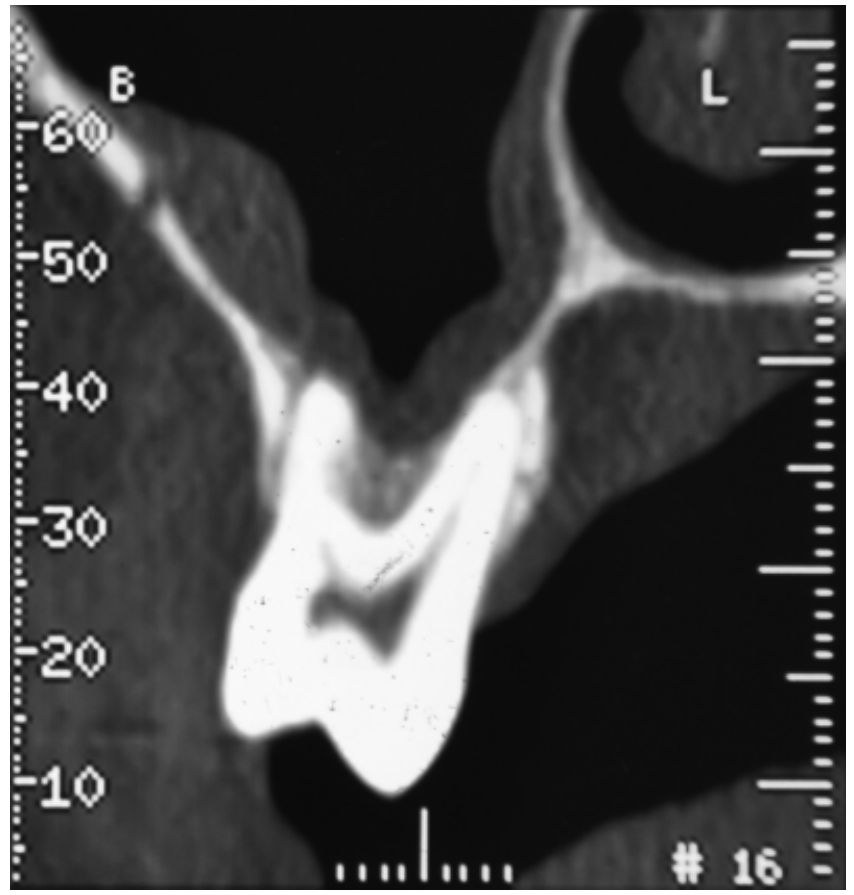

Fig. I. Transversal view of the computerized tomography scan of a sinus with an image of the artery is inside the bone (intraosseous).

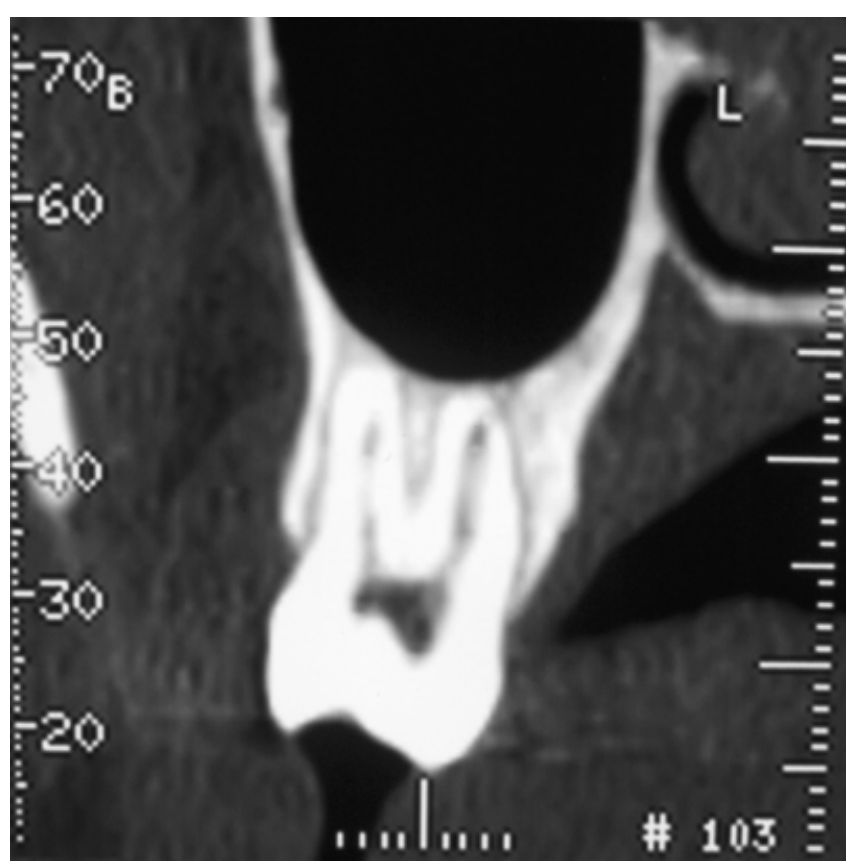

Fig. 2. Transversal view of the computerized tomography scan of a sinus with an image of the artery stays below the Schneiderian membrane.

Maxillary pathology and presence of sinus septa (Fig. 4) were recorded for each sinus. The diameter of the canal was also analyzed with regard to age, gender and location (right or left).

\section{Statistical analysis}

Graph Pad Instat 3.00 for windows (Graph Pad Software Inc., San Diego, CA, USA) was used for all statistical analysis. Mean values were recorded for each parameter and standard deviations were calculated. Pearson correlation rank was used for correlations between diameter of the canal and age. Unpaired $t$ test was also used to determine the difference between men and women. Intraobserver agreement was calculated using intraclass correlation coefficients (ICCs). 


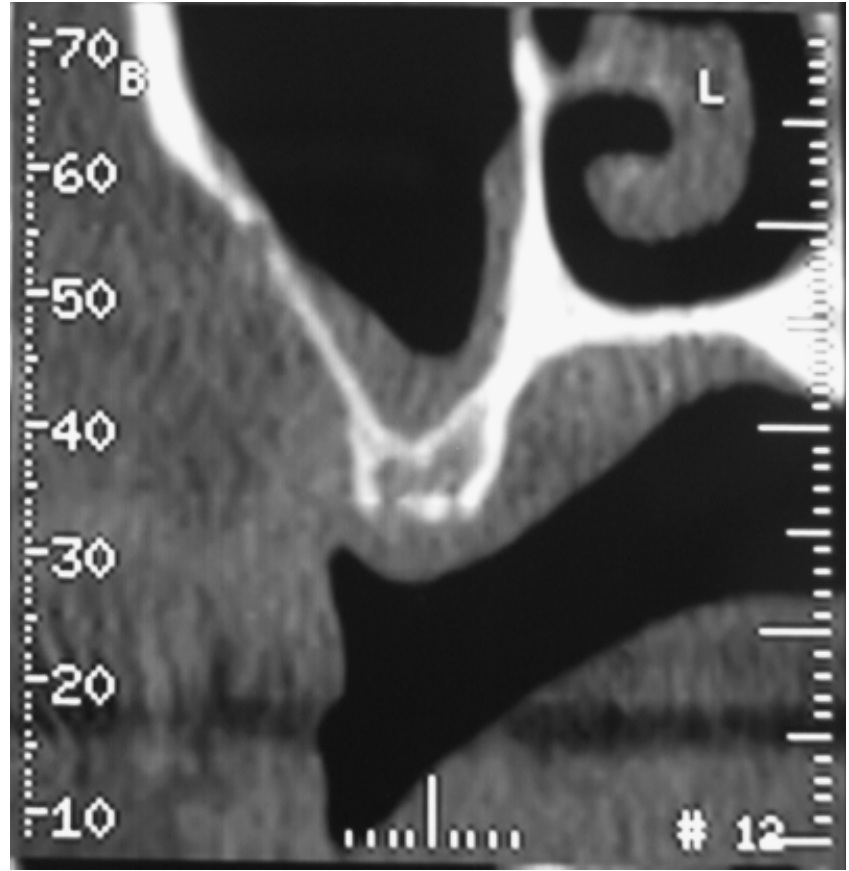

Fig. 3. Transversal view of the computerized tomography scan of a sinus with an image of the artery is on the outer cortex of the lateral sinus wall.

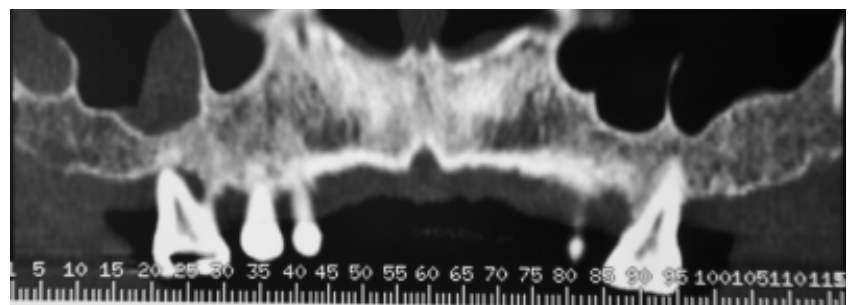

Fig. 4. The existence of maxillary pathology in the right sinus. Both left and right sinus regions represent sinus septa.

\section{Results}

The ICC was 0.8I. Totally, 3 I 5 axial sections were examined. Prevalence of sinus septa and sinus pathology (including membrane thickening, chronic sinusitis, cysts) was I6.I\% and $24.8 \%$, respectively. Artery was visualized in $64.5 \%$ of all sinuses and was mostly intraosseous $(68.2 \%), 26 \%$ was below the Schneiderian membrane and only $5.7 \%$ was detected on the outer cortex of the lateral sinus wall. Mean diameter of PSAA was found to be $\mathrm{I} .3 \pm 0.5 \mathrm{~mm}$. For right and left sinuses, these values were recorded to be $\mathrm{I} .3 \pm 0.5$ and $\mathrm{I} .2 \pm 0.5 \mathrm{~mm}$, respectively. Lower border of the artery to the alveolar crest was $\mathrm{I} 8 \pm 4.9 \mathrm{~mm}$ and this was $\mathrm{I} 8 . \mathrm{I} \pm 4.9 \mathrm{~mm}$ for right sinus and $\mathrm{I} 8 \pm 4.9 \mathrm{~mm}$ for left one (Table I). Distance of the artery to the medial sinus wall was I I $\pm 3.8 \mathrm{~mm}$. When diameters of the arteries were classified, $36.1 \%$ of the artery was $\leq \mathrm{I} \mathrm{mm} ; 5 \mathrm{I} .4 \%$ was $\mathrm{I}-2 \mathrm{~mm}$, and $\mathrm{I} 2.3 \%$ was $\geq 2 \mathrm{~mm}$. There was no statistically significant difference detected between the age of men and women $(P=0.098)$. The mean diameter of the artery was $\mathrm{I} .4 \pm 0.4 \mathrm{~mm}$ in men and $\mathrm{I} .2 \pm 0.4 \mathrm{~mm}$ in women $(P<0.000 \mathrm{I})$ and the difference was also significant in both right $(P=0.017)$ and left sites $(P=0.0002)$. The artery was detected in $29.6 \%$ of men and $61.3 \%$ women.

No significant correlation between the diameter of the artery and age was observed in both right and left sites $(r=0.05, P=0.639$ for right site; $r=0.035, P=0.75$ for left site).

\section{Discussion}

Placement of endosseous implants in the atrophic posterior maxilla has become a common procedure in recent years as a result of improved biologic understanding of healing and the availability of bone grafting materials to augment the maxillary sinus (Regev et al. I995). During this procedure, care should be taken on anatomic structure of the area.

Results from this study showed that sinus septa were present in I6.I\% of the 242 sinuses examined. Literature has reported similar ranges,
Table 1. Average diameter of posterior superior alveolar artery and the distance between lower border of the artery to the alveolar crest in right and left sites

\begin{tabular}{lll}
\hline & $\begin{array}{l}\text { Distance }(D) \\
\text { Mean } \\
\text { Min-max } \\
\text { Median }\end{array}$ & $\begin{array}{l}\text { Average diameter } \\
\text { Mean } \\
\text { Min-max } \\
\text { Median }\end{array}$ \\
\hline Left $(\mathrm{mm})$ & $18 \pm 4.9$ & $1.2 \pm 0.5$ \\
& $2.8-31.7$ & $0.2-3.2$ \\
& 18.2 & 1.2 \\
Right $(\mathrm{mm})$ & $18.1 \pm 4.9$ & $1.3 \pm 0.5$ \\
& $6.3-31.7$ & $0.4-3.5$ \\
& 17.9 & 1.2 \\
Total $(\mathrm{mm})$ & $18 \pm 4.9$ & $1.3 \pm 0.5$ \\
& $2.8-31.7$ & $0.2-3.5$ \\
& 18.1 & 1.2 \\
\hline \multirow{2}{*}{ D, lower border of the artery } & to the alveolar crest. \\
\hline
\end{tabular}

I6\% (Krennmair et al. I997), 26.5\% (Kim et al. 2006) when CT was used to assess 200 sinuses. However, a recent published cone beam CT study reported much higher prevalence $133.2 \%$ in 1029 sinuses) (Neugebauer et al. 20I0). This is because the method they used to detect and describe the septa. Nonetheless, in anatomic specimens, Gosau et al. (2009) found $27 \%$ and Krennmair et al. (1999) found I $8.3 \%$ prevalence of septum, which is close to current study observation.

In the present study, it was possible to identify the presence and location of vessels with CT scans. Artery was visualized in $64.5 \%$ of the examined 242 sinuses. The results correlate well with previous publications (Elian et al. 2005; Mardinger et al. 2007). Elian et al. (2005) and Mardinger et al. (2007) reported the prevalence of $52.9 \%$ and $55 \%$, respectively. Whereas Elian et al. (2005) only examined the intraosseous branch of the artery on the outer or inner wall if it was detectable. This may explain the higher incidence in our study. However, an endosseous anastomosis of PSAA and IOA was found in IOO\% of cadaveric specimens examined (Solar et al. I999; Traxler et al. I999; Rosano et al. 2009). This suggests that an undetected intrabony canal in a CT scan does not exclude its existence but merely implies that it may not be visible due to small diameter (Mardinger et al. 2007).

The artery was detected at a mean distance of I $8 \pm 4.9 \mathrm{~mm}$ from the alveolar ridge. In anatomic studies, this distance was I8.9-19.6 mm (Solar et al. I999; Traxler et al. I999). Present results were slightly lower but in good agreement with other anatomic studies (Solar et al. I999; Traxler et al. I999). In addition, the number of anatomic specimens used in other studies was much lower than the present study (I 8 vs. 242 ) (Solar et al. I999; Traxler et al. I999). Distances ranged between 2.8 and $31.7 \mathrm{~mm}$ in the present study. This wide range could be explained by the difference of vertical alveolar ridge dimensions and anatomic variation in the arteries position. 
Moreover, mean vertical ridge dimensions were I0.2 $\pm 4.8 \mathrm{~mm}$ in the present study. Thus, it could be calculated that the mean distance of the alveolar artery to the antral floor was $7.8 \pm 0.3 \mathrm{~mm}$. Therefore, it is recommended to be careful in atrophied ridges because superior osteotomy line is placed more caudal than normal position. This finding is consistent with that of Mardinger et al. (2007) as they also found a distance of $7-8 \mathrm{~mm}$ from the alveolar artery to the antral floor when the ridge height was either 5-IO $\mathrm{mm}$ or under $5 \mathrm{~mm}$.

Finding from this study reported a mean vessel diameter of $\mathrm{I} .3 \mathrm{~mm}$. The observation is in agreement with Ella et al. (2008), who found that the mean diameter of the vessels was I.2 mm overall. In anatomic studies, diameters of the PSAA and IOA were also investigated (Solar et al. I999; Traxler et al. I999). Mean diameters were $1.6 \mathrm{~mm}$ at their origin, ranging from I.2 to $2.7 \mathrm{~mm}$ (Solar et al. I999; Traxler et al. I999). However, anatomic study measurements were

\section{References}

Boyne, P.J. \& James, R.A. (I980) Grafting of the maxillary sinus floor with autogenous marrow and bone. Journal of Oral Surgery 38: 6I3-6I 6.

Elian, N., Wallace, S., Cho, S.C., Jalbout, Z.N. \& Froum, S. (2005) Distribution of the maxillary artery as it relates to sinus floor augmentation. International Journal of Oral e) Maxillofacial Implants 20: 784-787.

Ella, B., Sedarat, C., Noble Rda, C., Normand, E., Lauverjat, Y., Siberchicot, F., Caix, P. \& Zwetyenga, N. (2008) Vascular connections of the lateral wall of the sinus: surgical effect in sinus augmentation. International Journal of Oral \& Maxillofacial Implants 23: 1047-1052.

Gosau, M., Rink, D., Driemel, O. \& Draenert, F.G. (2009) Maxillary sinus anatomy: a cadaveric study with clinical implications. The Anatomical Record 292: 352-354.

Greenstein, G., Cavallaro, J., Romanos, G. \& Tarnow, D. (2008) Clinical recommendations for avoiding and managing surgical complications associated with implant dentistry: a review. Journal of Periodontology 79: $1317-1329$

Hur, M.S., Kim, J.K., Hu, K.S., Bae, H.E., Park, H.S. \& Kim, H.J. (2009) Clinical implications of the topography and distribution of the posterior superior alveolar artery. Journal of Craniofacial Surgery 20: $55 \mathrm{I}-554$.

Jensen, O.T., Shulman, L.B., Block, M.S. \& Iacono, V.J.

(1998) Report of the sinus consensus conference of done at the exit from the maxillary artery. When we calculated a mean value for each sinus from the examined sections, only $4.9 \%$ of the sinuses have vessels $\geq 2 \mathrm{~mm}$. Similarly, Mardinger et al. (2007) reported $6.7 \%$ of sinuses having vessels $\geq 2 \mathrm{~mm}$. This may explain why there is a very low incidence of intense bleeding during sinus augmentation procedure. However, during sinus lift procedure, it is possible to sever a blood vessel that runs along the membrane or cut an intraosseous artery in the lateral wall of the sinus, in these circumstances excessive bleeding may occur (Greenstein et al. 2008).

Although mean patient age was not statistically different in men and women, male patients had larger vessels in this study. Mean diameter of female arteries was I.I $\pm 0.3 \mathrm{~mm}$ and in male patients, it was $\mathrm{I} .4 \pm 0.4 \mathrm{~mm}(P<0.000 \mathrm{I})$. Mardinger et al. (2007) could not find a difference between men and women in the diameter of the canal. Furthermore, in the present study, diameter of the artery did not change according to age. Mardinger et al. (2007) found a relationship but the diameter was wider in older patients.

Preoperative imaging is highly clinically relevant for the evaluation of the presence of septa, localization of PSAA and existence of pathologies in maxillary sinus and these data may be used to alter the surgical approach to achieve a successful dental implant treatment.

\section{Conclusions}

The results from this study suggested that CT scan is a valuable tool in evaluating presence of sinus pathology, septa and arteries before maxillary sinus surgery. Although variations exist in every patient, the findings from this study suggest limiting the superior border of the lateral window up to $\mathrm{I} 8 \mathrm{~mm}$ from the ridge to avoid any potential vascular damage.
1996. International Journal of Oral es Maxillofacial Implants $\mathbf{3} 3$ (Suppl.): I I-45.

Kim, M.J., Jung, U.W., Kim, C.S., Kim, K.D., Choi, S.H., Kim, C.K. \& Cho, K.S. (2006) Maxillary sinus septa: prevalence, height, location, and morphology. A reformatted computed tomography scans analysis. Journal of Periodontology 77: 903-908.

Krennmair, G., Ulm, C. \& Lugmayr, H. (I997) Maxillary sinus septa: incidence, morphology and clinical implications. Journal of Craniomaxillofacial Surgery 25: 26I-265.

Krennmair, G., Ulm, C.W., Lugmayr, H. \& Solar, P. (I999) The incidence, location, and height of maxillary sinus septa in the edentulous and dentate maxilla. Journal of Oral and Maxillofacial Surgery 57: 667-67I; discussion 67I-662.

Mardinger, O., Abba, M., Hirshberg, A. \& SchwartzArad, D. (2007) Prevalence, diameter and course of the maxillary intraosseous vascular canal with relation to sinus augmentation procedure: a radiographic study. International Journal of Oral and Maxillofacial Surgery 36: 735-738.

Neugebauer, J., Ritter, L., Mischkowski, R.A., Dreiseidler, T., Scherer, P., Ketterle, M., Rothamel, D. \& Zöller, J.E. (20I0) Evaluation of maxillary sinus anatomy by cone-beam CT prior to sinus floor elevation. International Journal of Oral et Maxillofacial Implants 25: 258-265.
Regev, E., Smith, R.A., Perrott, D.H. \& Pogrel, M.A. (1995) Maxillary sinus complications related to endosseous implants. International Journal of Oral ↔) Maxillofacial Implants Io: 45 I-46I.

Rosano, G., Taschieri, S., Gaudy, J.F. \& Del Fabbro, M. (2009) Maxillary sinus vascularization: a cadaveric study. Journal of Craniofacial Surgery 20: 940-943.

Shibli, J.A., Faveri, M., Ferrari, D.S., Melo, L., Garcia, R.V., d'Avila, S., Figueiredo, L.C. \& Feres, U. (2007) Prevalence of maxillary sinus septa in I024 subjects with edentulous upper jaws: a retrospective study. Journal of Oral Implantology 33: 293-296.

Solar, P., Geyerhofer, U., Traxler, H., Windisch, A., Ulm, C. \& Watzek, G. (I999) Blood supply to the maxillary sinus relevant to sinus floor elevation procedures. Clinical Oral Implants Research го: 34-44.

Tatum, H. (I986) Maxillary and sinus implant reconstruction. Dental Clinics of North America 30: 207-229.

Tong, D.C., Rioux, K., Drangsholt, M. \& Beirne, O.R. (1998) A review of survival rates for implants placed in grafted maxillary sinuses using meta-analysis. International Journal of Oral \& Maxillofacial Implants I3: $175-182$.

Traxler, H., Windisch, A., Geyerhofer, U., Surd, R., Solar, P. \& Firbas, W. (I999) Arterial blood supply of the maxillary sinus. Clinical Anatomy I2: 417$42 \mathrm{I}$. 